\title{
A Fuzzy Approach to Retailers' Service Satisfaction Assessment in One Round Survey
}

\author{
Yong Li \\ Department of Automation Kunming University of Science and Technology, Yunnan, China \\ Dr.Leon@foxmail.com
}

\begin{abstract}
The service satisfaction of retailer is an important issue to assessment service quality of the most of competitive organizations in providing goods process. This paper propose a fuzzy approach for evaluating current perception of the service satisfaction of retailer in one round survey, and uses the degree of importance of the perception of current attributes to assure its' validation. Finally, a sample of 50 cigarette retailers' service satisfaction assessment is used to implement the proposed method. Some interesting conclusions and useful suggestions are given to the organizations that to improve the service quality.

Index Terms - Service satisfaction, fuzzy entropy, SERVQUAL.
\end{abstract}

\section{Introduction}

The impact of the shift to retailer power in the organizations (manufacturers or a wholesaler) - retailer relationship challenges the mass production mentality and challenges organizations to focus on developing customer closeness as a way to provide higher levels of service operations effectiveness. For those organizations, understanding exactly what retailers expect and want is the most crucial step in defining and delivering the high quality service [1]. The SERVQUAL method is widely used by many researchers to evaluate service satisfaction [10]. The method has five dimensions to measure service quality, including the Tangibles, Reliability, Responsiveness, Assurance and Empathy [9], which implemented with a questionnaire use Likert scales to measure respondents' attitude. Organizations evaluate the service satisfaction of customers by determining whether there is any gap between of customers' expectations and perceptions in the five dimensions. Since human judgments and preference are often vague and can't estimate his preference with an exact numerical value. It is more realistic to use lingual expressions to describe the desired value, e.g. "very low", "low", "fair", "high", "very high", "strongly", "somewhat", and "undecided", "satisfied", "dissatisfied", etc. [2]. Due to this type of existing fuzziness in the survey process, fuzzy set theory is an appropriate method for dealing with uncertainty.

Normally, the evaluation of service quality is an on-going process that requires continuous monitoring to maintain high levels of service quality across a number of different service attributes. It need at least 2 round surveys to test whether the measurement tool suggests changes in common values (attributes).This paper proposed a fuzzy method to assessment the organization service quality at one round based on the author's formal research. Finally, this assessment model is tested by a case of a tobacco group in Yunnan province.

\section{Research Methodology}

Conventionally designed questionnaire frequently use a Likert scales to gauge the feeling of respondents. The parameters associated with the membership function are provided by expert judgments. The questionnaire sought the satisfaction level of the experts concerning the retailers using a 7-point Likert scales. Experts were asked to evaluate different cognitive levels given each grade of candidate retailer according to subjective perceptions. Additionally, the presence of the values is defined using fuzzy membership functions and then giving the membership degree of the service type at a specified level is taken through fuzzy intersection function. Considering the nature of the problem, the use of a predefined parameterized $\boldsymbol{S}$-shaped membership function is preferred [3]. Further, the fuzzy measures of uncertainty service satisfaction assessment are executed through fuzzy entropy.

The construction of value membership function. The membership function $\mu_{v}\left(\bar{x}_{i}\right)$ generating for service satisfaction value is given in (1). Here, $\bar{x}_{i}$ denotes the average of all retailers' judgments for a given value $i$.

$$
\mu_{v}\left(\bar{x}_{i}\right)=\left\{\begin{array}{cl}
0 & \text { if } \bar{x}_{i} \leq 5 \\
\left(\bar{x}_{i}-5\right) / 2 & \text { if } 5<\bar{x}_{i}<7 \\
1 & \text { if } \bar{x}_{i} \geq 7
\end{array} .\right.
$$

For instance, if $\bar{x}_{i}$ is greater than 5 , then it can be concluded the most of retailers think the service completely has the value $i$. Therefore, it can be inferred the service certainly has this value and the membership value should be 1 . Similarly, if $\bar{x}_{i}$ is smaller than 5, it indicates the retailers think the service does not have the value $i$. So the membership value 0 can be easily assigned. Additionally, a linear membership function is assumed for the $\bar{x}_{i}$ values between 5 and 7. Thus, the membership degree shows to what extent the service presents a value represented by a particular fuzzy set.

1) Fuzzy intersection functions in service satisfaction value. When the presence of the values is defined using fuzzy membership functions, the presence of service satisfaction will also have a fuzzy characteristic. To transform the membership degrees of the values to service satisfaction membership degrees, a concept derived from the intersection of fuzzy sets is used as follows:

if $\mathrm{m}$ values are used to measure a service satisfaction at a level, and n number of these values should exist to accept the 
existence of the service satisfaction at that level, then the $\mathrm{m}$ values are used to make combinations of sets with $n$ members, thus giving the minimum membership degree within a combination and then the maximum among combinations is taken, this will give the membership degree of the service type at a specified level. The mathematical formulation is given as following [4][5]:

$$
\mu_{S-L}(\bar{X})=\sup _{r_{1}, r_{2}, \cdots, r_{n} \in S S}\left\{\hat{k}_{k=1}^{m} \mu_{v}\left(\bar{x}_{r_{k}}\right)\right\} .
$$

Where $S$ - $L$ denotes the service satisfaction level and SS indicates the service satisfaction set; and $\bar{X}$ is a vector of all the average values of the retailers.

2) The fuzzy measures of uncertainty in service satisfaction assessment. For any service, the values of a service satisfaction set belong to the set to some degree. Fuzzy entropy is the most well-known measure of fuzziness, which estimates the average ambiguity in fuzzy sets in some welldefined sense [6]. In this study, the measure of fuzziness for a discrete fuzzy set $A$ is defined as a mapping $H: P_{n}(X) \rightarrow R^{+}$ quantifies the degree of fuzziness present in $A$ in which $P_{n}(X)$ is the set of all fuzzy subsets of $X$. A measure of fuzziness should satisfy at least the five well-known properties [7], and a non-probabilistic entropy measure based on the membership functions of the intersection and union of the set and its complement set is used, which is introduced in [5][8], satisfies all properties and is defined as:

$$
H(A)=\frac{1}{n} \sum_{i=1}^{n} \frac{\mu_{A \cap A^{\prime}}\left(\bar{x}_{i}\right)}{\mu_{A \cup A^{\prime}}\left(\bar{x}_{i}\right)} .
$$

Where $n$ denotes the number of values in a service satisfaction type; $\bar{x}_{i}$ is the average of all respondents' judgments for a given value $i$ and $\mu_{v}\left(\bar{x}_{i}\right)$ denotes the degree of belongingness of value $i$ to the service satisfaction set $A . A^{\prime}$ is the complement set of $A$.

\section{Case Survey: Data Analysis and Results}

\section{A. Data Collection and Measures}

The authors implemented the questionnaire in one round based on the definition of questionnaire with 7 point Likerttypes proposed in our formal research. 50 retailers made a choice among 28 service alternatives showing service information about the cigarette supply characteristics derived from the 5 service types, after which they were interviewed about the reasons underlying their choice. Three different decision levels (average, high, very high) to identify the possible types of service satisfaction present in the organization have been defined. Table II gives the corresponding numbers of values for each level and type of service satisfaction. For instance, Tangibles consist of three values (A1-A3). While the number of "average" level is 1 means that only one of three value sets belonging to Tangibles, the service satisfaction has the "average" degree in Tangibles, similarly, the number of "high" level is 2 means that any two of three value sets belonging to Tangibles, the service satisfaction has the "high" degree in Tangibles. As well as the type of Reliability consist of 6 values (B1-B6), and to state "the service has the Reliability at average level" the service should be identified as having any three of these values.

\begin{tabular}{|c|c|}
\hline Service criteria & Questions \\
\hline A.Tangibles & $\begin{array}{l}\text { A1.Service personnel dress uniform and clean, } \\
\text { bring with complete certifications. } \\
\text { A2.For all important services, service personnel } \\
\text { make a clear service promise, for example, the } \\
\text { complaint accepted } 100 \% \text {. } \\
\text { A3. There are clear service instructions and as well } \\
\text { as others that can contribute to enhance the tangible } \\
\text { items of the QOS and the image of the company, } \\
\text { such as certification signs or sale gifts. }\end{array}$ \\
\hline B. Reliability & $\begin{array}{l}\text { B1.Service personnel can keep their promises, do } \\
\text { what they said. } \\
\text { B2.Service personnel can answer retailers' } \\
\text { questions patiently. } \\
\text { B3.Service personnel can treatment warmly on } \\
\text { retailers' needs. } \\
\text { B4.Supply allocation is fair and equitable. } \\
\text { B5.Retailer can be kept informed of the supplies } \\
\text { information. } \\
\text { B6.Retailer has reasonable profit margins. }\end{array}$ \\
\hline C. Responsiveness & $\begin{array}{l}\text { C1.Service personnel always provide fast service. } \\
\text { C2.Even they are busy, service personnel still } \\
\text { respond retailers' requirements. } \\
\text { C3.Even if they can not immediately resolve } \\
\text { question, service personnel can reply in time. } \\
\text { C4.Delivery accurate, timely. } \\
\text { C5.Retailers are kept informed of the products and } \\
\text { relevant market. } \\
\text { C6.There are telephone and other consulting and } \\
\text { complaints channels for retailers' communicating } \\
\text { with service personnel. } \\
\text { C7.Phone ordering is convenient, fast. } \\
\text { C8.Network ordering is convenient, fast. }\end{array}$ \\
\hline D. Assurance & $\begin{array}{l}\text { D1. The attitude of service personnel is polite, warm } \\
\text { and thoughtful during service process. } \\
\text { D2.Sevice personnel are familiar with the } \\
\text { performance of products. } \\
\text { D3.Service personnel can provide effective } \\
\text { guidance on retailers' sales. } \\
\text { D4.Service personnel are able to provide the } \\
\text { necessary market support, such as promotion. } \\
\text { D5.Service personnel are positive in anti- } \\
\text { counterfeiting and cleaning up the market. } \\
\text { D6. Service personnel are familiar with market. } \\
\text { D7.Ensuring the rational distribution of retail } \\
\text { outlets, avoiding vicious competition among } \\
\text { retailers. } \\
\text { D8.Service personnel have ability to grasp } \\
\text { information about retailers' demands. }\end{array}$ \\
\hline E. Empathy & $\begin{array}{l}\text { E1.Service personnel can know initiatively the } \\
\text { retailers' demands at any time. } \\
\text { E2.Provide targeted services for the different } \\
\text { demands of different retailers. } \\
\text { E3.Increasing ordering channels, offering a variety } \\
\text { of ordering ways, such as network ordering etc. }\end{array}$ \\
\hline
\end{tabular}

TABLE I Questionnaire Items 
TABLE II Numbers of Values for Each Decision Level and Service Satisfaction Type

\begin{tabular}{|c|c|c|c|c|c|}
\hline \multirow{2}{*}{ Service criteria } & \multirow{2}{*}{ Value set } & \multirow{2}{*}{$\begin{array}{c}\text { Total } \\
\text { number } \\
\end{array}$} & & \multicolumn{3}{|c|}{ Decision levels } \\
\cline { 4 - 6 } & of values & Average & High & $\begin{array}{c}\text { Very } \\
\text { high }\end{array}$ \\
\hline A. Tangibles & A1-A3 & 3 & 2 & 3 & 3 \\
\hline B. Reliability & B1-B6 & 6 & 3 & 4 & 5 \\
\hline C. Responsiveness & C1-C8 & 8 & 4 & 5 & 6 \\
\hline D. Assurance & D1-D8 & 8 & 4 & 5 & 6 \\
\hline E. Empathy & E1-E3 & 3 & 2 & 3 & 3 \\
\hline
\end{tabular}

TABLE III Results of the Questionnaire and Membership Degrees of Service Satisfaction Values

\begin{tabular}{|c|c|c|c|c|c|}
\hline \multirow{2}{*}{ Value } & \multirow{2}{*}{$\boldsymbol{i}$} & \multicolumn{2}{c|}{ Current values } & \multicolumn{2}{c|}{ Importance of values } \\
\cline { 3 - 6 } & & $\bar{x}_{i}$ & $\mu_{v}\left(\bar{x}_{i}\right)$ & $\bar{y}_{i}$ & $\mu_{v}\left(\bar{y}_{i}\right)$ \\
\hline A1 & 1 & 6.18 & 0.59 & 5.74 & 0.37 \\
\hline A2 & 2 & 6.2 & 0.6 & 6.12 & 0.56 \\
\hline A3 & 3 & 6.16 & 0.58 & 5.68 & 0.34 \\
\hline B1 & 4 & 6.34 & 0.67 & 6.16 & 0.68 \\
\hline B2 & 5 & 6.5 & 0.75 & 6.34 & 0.67 \\
\hline B3 & 6 & 6.52 & 0.76 & 6.28 & 0.64 \\
\hline B4 & 7 & 6.28 & 0.64 & 6.54 & 0.77 \\
\hline B5 & 8 & 6.3 & 0.65 & 6.22 & 0.61 \\
\hline B6 & 9 & 6.14 & 0.57 & 6.22 & 0.61 \\
\hline C1 & 10 & 6.36 & 0.68 & 6.16 & 0.58 \\
\hline C2 & 11 & 6.34 & 0.67 & 6.1 & 0.55 \\
\hline C3 & 12 & 6.58 & 0.79 & 6.18 & 0.59 \\
\hline C4 & 13 & 6.56 & 0.78 & 6.3 & 0.65 \\
\hline C5 & 14 & 6.2 & 0.6 & 6.1 & 0.55 \\
\hline C6 & 15 & 6.3 & 0.65 & 6.04 & 0.52 \\
\hline C7 & 16 & 6.02 & 0.51 & 5.78 & 0.39 \\
\hline C8 & 17 & 6.41 & 0.71 & 6.32 & 0.66 \\
\hline D1 & 18 & 6.42 & 0.71 & 6.28 & 0.64 \\
\hline D2 & 19 & 6.32 & 0.66 & 6.06 & 0.53 \\
\hline D3 & 20 & 6.38 & 0.69 & 6.14 & 0.57 \\
\hline D4 & 21 & 6.18 & 0.59 & 6.0 & 0.5 \\
\hline D5 & 22 & 6.4 & 0.7 & 6.47 & 0.74 \\
\hline D6 & 23 & 6.36 & 0.68 & 6.24 & 0.62 \\
\hline D7 & 24 & 6.3 & 0.65 & 6.32 & 0.66 \\
\hline D8 & 25 & 6.44 & 0.72 & 6.32 & 0.66 \\
\hline E1 & 26 & 6.3 & 0.65 & 6.2 & 0.6 \\
\hline E2 & 27 & 6.3 & 0.65 & 6.02 & 0.51 \\
\hline E3 & 28 & 6.53 & 0.77 & 6.18 & 0.59 \\
\hline & & & & & \\
\hline
\end{tabular}

$i$ : Number of value.

$\bar{x}_{i}, \bar{y}_{i}$ : Average of responses for value $i$ in the current option and the importance option.

$\mu_{v}\left(\bar{x}_{i}\right), \mu_{v}\left(\bar{y}_{i}\right)$ : Membership degree of value $i$ in the current option and the importance option, respectively.

\section{B. Assessing Suppliers' Service Quality for Retailer}

For evaluate suppliers' service quality for retailers, the initial step in the fuzzy-based methodology is to collect data through a self-administered questionnaire. After collecting data with the questionnaire, the average of responses is used to calculate the membership degrees for each service satisfaction value using (1). The extent of the average of responses to service satisfaction values is shown in Table III. For example, in terms of current values the average of responses for the value $\mathrm{A} 3, \bar{x}_{3}$ is 6.16 and when it is applied to (1) the membership degree is calculated as follows:

$$
\mu_{v}(5.68)=\frac{(6.16-5)}{2}=0.58 \text {. }
$$

According to the results given in Table III, B2, B3, C3, $\mathrm{C} 4, \mathrm{C} 8, \mathrm{D} 1, \mathrm{D} 5, \mathrm{D} 8$ and E3 are the strongest values in terms of current service satisfaction value, i.e., the retailer holds these values. The service can also be said to have A2, B1, B4, B5, C1, C2, C5, C6, D2, D3, D6, D7, E1, E2, because these values have moderately strong membership degrees $(>0.6)$.

It can be observed that current service satisfaction values of retailers are divided into two main groups by the option important. This can be explained as those values $\{\mathrm{B} 1, \mathrm{~B} 2, \mathrm{~B} 3$, B4, B5, C4, C8, D1, D5, D6, D7, D8, E1 \} which are both common (current) and important are service satisfaction values that have really been perceived and identified by the retailers, while those values $\{\mathrm{A} 2, \mathrm{C} 1, \mathrm{C} 2, \mathrm{C} 3, \mathrm{C} 5, \mathrm{C} 6, \mathrm{D} 2, \mathrm{D} 3, \mathrm{E} 2, \mathrm{E} 3\}$, which are current but not important are again service satisfaction, but indicate that they are service satisfaction values because of the retailers complies with. The values $\{\mathrm{B} 6\}$ not common but are important could be considered as espoused service satisfaction values and these values affect the internal forces of the retailers. And then, the values $\{\mathrm{A} 1, \mathrm{~A} 3$, C7, D4 \} both not common and not important could be considered as pointless service satisfaction values and these values can not affect service satisfaction for the retailers, so the values would be discarded.

\section{The Membership's Roles of Service Satisfaction}

Using (2), the membership degrees of service types at different levels, which indicate the existence of each service type in the cigarette supply for retailers, are calculated as given in Table IV. Also, the fuzzy entropy measures for each service type are given in Table IV as a result of (3).

TABLE IV Membership Degrees and Fuzzy Entropy Measures of Service Satisfaction Types

\begin{tabular}{|l|c|l|l|l|}
\hline \multirow{2}{*}{ Service criteria } & \multirow{2}{*}{$\begin{array}{c}\text { Value set Fuzzy } \\
\text { entropy H(.) }\end{array}$} & \multicolumn{3}{|c|}{ Decision levels } \\
\cline { 3 - 5 } & 0.67 & 0.6 & 0.6 & 0.6 \\
\hline Tangibles & 0.50 & 0.67 & 0.65 & 0.64 \\
\hline Reliability & 0.44 & 0.67 & 0.67 & 0.65 \\
\hline Responsiveness & 0.46 & 0.68 & 0.68 & 0.66 \\
\hline Assurance & 0.47 & 0.65 & 0.65 & 0.65 \\
\hline Empathy & & & & \\
\hline
\end{tabular}

An example of the calculation of the membership degree of the service type at the average level (Service-Level (S-L): Empathy - Average) is given below:

From Table II, n equals 2 and SS is $\{26,27,28\}$. Then, 


$$
\begin{aligned}
& \mu_{\text {Empathy-Average }}(\bar{x})=\sup _{r_{1}, r_{2} \in\{26,27,28\}}\left\{\stackrel{2}{\left.\stackrel{\wedge}{k=1} \mu_{v}\left(\bar{x}_{r_{k}}\right)\right\}}\right. \\
& =\sup \left\{\wedge\left(\mu_{v}\left(\bar{x}_{1}\right), \mu_{v}\left(\bar{x}_{2}\right)\right) ; \wedge\left(\mu_{v}\left(\bar{x}_{1}\right), \mu_{v}\left(\bar{x}_{3}\right)\right) ; \wedge\left(\mu_{v}\left(\bar{x}_{2}\right), \mu_{v}\left(\bar{x}_{3}\right)\right)\right\} \\
& =\sup \{\wedge(0.65,0.65) ; \wedge(0.65,0.77) ; \wedge(0.65,0.77)\} \\
& =0.65 .
\end{aligned}
$$

The service satisfaction value indicates the product supply service has at least an average level of Empathy role with the membership degree of 0.65. We denote Empathy as $A$. Furthermore, an example calculation of the fuzzy entropy measure for $A$ is given below:

$$
\begin{aligned}
& H(A)=\frac{1}{3} \sum_{i=1}^{3} \frac{\mu_{A \cap A^{\prime}}\left(\bar{x}_{i}\right)}{\mu_{A \cup A^{\prime}}\left(\bar{x}_{i}\right)} \\
& =\frac{1}{3}\left(\frac{\min \left(\mu\left(x_{1}\right) ; 1-\mu\left(x_{1}\right)\right)}{\max \left(\mu\left(x_{1}\right) ; 1-\mu\left(x_{1}\right)\right)}+\frac{\min \left(\mu\left(x_{2}\right) ; 1-\mu\left(x_{2}\right)\right)}{\max \left(\mu\left(x_{2}\right) ; 1-\mu\left(x_{2}\right)\right)}\right. \\
& \left.\quad+\frac{\min \left(\mu\left(x_{3}\right) ; 1-\mu\left(x_{3}\right)\right)}{\max \left(\mu\left(x_{3}\right) ; 1-\mu\left(x_{3}\right)\right)}\right) \\
& =\frac{1}{3}\left(\frac{\min (0.65 ; 0.35)}{\max (0.65 ; 0.35)}+\frac{\min (0.65 ; 0.35)}{\max (0.65 ; 0.35)}+\frac{\min (0.77 ; 0.23)}{\max (0.77 ; 0.23)}\right) \\
& =0.47 .
\end{aligned}
$$

Using the same method, the membership degree of the service types at high and very high level are given below:

$$
\begin{aligned}
& \mu_{\text {Empathy-High }}(\bar{x})=\sup _{r_{i}, r_{2}, r_{3} \in\{26,27,28\}}\left\{\hat{k=1} \mu_{v}\left(\bar{x}_{r_{k}}\right)\right\} \\
& =\sup \left\{\wedge\left(\mu_{v}\left(\bar{x}_{1}\right), \mu_{v}\left(\bar{x}_{2}\right), \mu_{v}\left(\bar{x}_{3}\right)\right)\right\} \\
& =\sup \{\wedge(0.65,0.65,0.77)\}=0.65 .
\end{aligned}
$$

The high level of Empathy has the same number of the very high level, so it have the same membership degree 0.65.

\section{Conclusion}

From Table IV, it can be concluded according to the decision level "High" that the product supply shows the characteristics of Assurance, Responsiveness, Empathy, Reliability and Tangibles from its service satisfaction values. Here, the product supply has service of Assurance with a membership degree of 0.68 , indicating a quite strong and dominant value in D1, D2, D3, D5, D6, D7, and D8 (Table I). If the decision level is increased to "very high", the conclusion is same. However, Responsiveness, Reliability, Empathy and Tangibles show the same characteristics.

A further measure, fuzzy entropy, that may contribute to a more consistent and accurate judgment, is considered. This measure reveals the degree of uncertainty inherent in each value set we are exposed to in any judgment about these value sets. A value close to one indicates high uncertainty. Table IV shows Tangibles is the most uncertain value set with a fuzziness of 0.67 . This service type implies high uncertainty and thus poor judgment about the value set (A2). The high uncertainty and moderate membership degree can be implied from the indecision. In this context, although Reliability presents the nearly second highest value at "Average", "High" and "Very high" decision levels will not be considered for the product supply. Tangibles is the third uncertain value set with a fuzziness of 0.63 , and it presents the highest value at "Average", "High" and "Very high" decision level will also mainly be considered for the product supply.

The Assurance with a second relatively low degree of fuzziness (0.46) and the first degree of membership at all decision levels can be implied to be the most important part of the service satisfaction. Finally, the assessment concludes Reliability, Responsiveness, Assurance and Empathy form the values of service satisfaction in this one round survey. And the authors find the results of questionnaire are more appropriate and accurate items than those proposed in our formal research.

\section{References}

[1] Jose A. Martinez and Laura Martinez, "Some insights on conceptualizing and measuring service quality", Retailing and Consumer Services, vol. 17, no.1, pp.29-42, September 2010.

[2] S. Vinodh, R. Anesh Ramiya, and S. G. Gautham, "Application of fuzzy analytic network process for supplier selection in a manufacturing organisation", Expert Systems With Applications, vol. 38, no.1, pp. 272280, Qctober 2011.

[3] D. Dubois and H. Prade, "The three semantics of fuzzy sets", Fuzzy Set and Systems, vol.90, no.2, pp.141-150, Qctober 1997,

[4] S. Medasani, J. Kim, and R. Krishnapuram, "An overview of membership function generation techniques for pattern recognition", Approximate Reasoning, vol.19, no.3-4, pp.391-417, March 1998.

[5] N. R. Pal, "On quantification of different facets of uncertainty", Fuzzy Sets and Systems, vol.107, no.1, pp.81-91, Qctober 2004.

[6] L. A. Zadeh, "Probability measures of fuzzy events", Mathematical analyses and Applications, vol.23, no.2, pp.421-427, August 1968.

[7] G. J. Klir and B. Yuan, Fuzzy Sets and Fuzzy Logic: Theory and Applications, Prentice Hall, New Jersey, 1995.

[8] X. G. Shang and W. S. Jiang, "A note on fuzzy information measures", Pattern Recognition Letters, vol.18, no.5, pp.425-432, May 1997.

[9] M. A. Badri, M. Abdulla, and A. AI-Madani. "Information technology center service quality: Assessment and application of SERVQUAL", International Journal of Quality \& Reliability Management, vol. 22, no. 8, pp. 819-848, 2005.

[10] R. Ladhari. "A review of twenty years of SERVQUAL research", International Journal of Quality and Service Sciences, vol.1, no.2. pp.172-198, 2009. 